\title{
ФУНКЦИОНААЬНАЯ ЭФФЕКТИВНОСТЬ
}

КАЕТОЧНО-ИНЖЕНЕРНОЙ КОНСТРУКЦИИ ПЕЧЕНИ

НА ОСНОВЕ ТКАНЕСПЕЦИФИЧЕСКОГО МАТРИКСА

(ЭКСПЕРИМЕНТАЛЬНАЯ МОАЕАЬ ХРОНИЧЕСКОЙ ПЕЧЕНОЧНОЙ НЕАОСТАТОЧНОСТИ)

\author{
М.Ю. Шагидулинн, ${ }^{l, ~ Н . А . ~ О н и щ е н к о ~}{ }^{l}$ Ю.Б. Басок ${ }^{l}$, А.М. Григорьев ${ }^{l}$, А.Д. Кириллова ${ }^{1}$, \\ Е.А. Немей, Е.А. Волкова', И.М. Ильинский, Н.П. Можейко ${ }^{1}$ В.И. Севастьянов", \\ C.B. Гombe $e^{1,2}$ \\ ' ФГБУ «Национальный меАицинский исслеАовательский центр трансп^антологии \\ и искусственных органов имени акалемика В.И. Шумакова» МинзАрава России, Москва, \\ Российская Фелерация \\ 2 ФГАОУ ВО «Первый Московский госуАарственный меАицинский университет \\ имени И.М. Сеченова» Минзарава России (Сеченовский университет), Москва, \\ Российская Фелерация
}

\begin{abstract}
Цель. Исследовать на экспериментальной модели хронической печеночной недостаточности (ХПН) функциональную эффективность клеточно-инженерной конструкции (КИК) печени на основе тканеспецифического матрикса из фрагментов децеллюляризованной печени крысы, аллогенных клеток печени и мультипотентных мезенхимальных стромальных клеток костного мозга (ММСК КМ). Материалы и методы. При создании КИК печени источниками печени для децеллюляризации и клеток печени были крысы-самцы породы Вистар, ММСК КМ выделяли из костного мозга крыс. Функциональную эффективность КИК исследовали на экспериментальной модели ХПН, получаемой затравкой крыс раствором $\mathrm{CCl}_{4}$. На разных сроках после имплантации результаты оценивали по биохимическим показателям цитолиза, гистохимическими методами анализировали морфологические изменения в печени в контрольной (введение в паренхиму печени физиологического раствора) и экспериментальной (введение в паренхиму печени КИК печени) группах. Результаты. Показано, что имплантация предложенной КИК обеспечивает более быструю нормализацию биохимических показателей крови и структурных нарушений поврежденной печени крыс (к 30 суткам после введения КИК вместо 180 суток в контроле) и снижение летальности животных с 50 до $0 \%$, что обусловлено более ранней активацией процессов пролиферации жизнеспособных клеток печени и более быстрым формированием новых кровеносных сосудов. Наблюдаемые эффекты можно объяснить либо стимулированием внутреннего регенеративного потенциала поврежденной печени при имплантации КИК, либо длительным функционированием пересаженных клеток в составе КИК на основе децеллюляризованного матрикса печени. Заключение. Полученные результаты доказывают наличие функциональной активности КИК печени, имплантируемой в паренхиму печени лабораторным животным с моделью ХПН.
\end{abstract}

Ключевые слова: печень, печеночная недостаточность, регенерачия, клеточно-инженерные конструкции, биоискусственные органы, матриксы.

\footnotetext{
Для корреспонденции: Шагидулин Мурат Юнусович. Адрес: 123182, Москва, ул. Щукинская, д. 1.

Тел. (499) 196-87-90. E-mail: dr.shagidulin@mail.ru

Corresponding author: Murat Shagidulin. Address: 1, Shchukinskaya str., Moscow, 123182, Russian Federation.

Phone: (499) 196-87-90. E-mail: dr.shagidulin@mail.ru
} 


\title{
FUNCTIONAL EFFICIENCY OF CELL-ENGINEERED LIVER CONSTRUCTS BASED ON TISSUE-SPECIFIC MATRIX (EXPERIMENTAL MODEL OF CHRONIC LIVER FAILURE)
}

\author{
M.Yu. Shagidulin ${ }^{1,2}$, N.A. Onishchenko ${ }^{1}$, Yu.B. Basok ${ }^{l}$, A.M. Grigoriev ${ }^{l}$, A.D. Kirillova ${ }^{l}$, \\ E.A. Nemets ${ }^{l}$, E.A. Volkova ${ }^{1}$, I.M. Iljinsky ${ }^{l}$, N.P. Mozheiko ${ }^{l}$, V.I. Sevastianov ${ }^{l}$, S.V. Gautier ${ }^{1,2}$ \\ ' Shumakov National Medical Research Center of Transplantology and Artificial Organs, Moscow, \\ Russian Federation \\ ${ }^{2}$ Sechenov University, Moscow, Russian Federation
}

\begin{abstract}
Objective: to investigate the functional efficiency of a cell-engineered construct (CEC) of the liver based on tissuespecific matrix consisting of decellularized rat liver fragments, allogeneic liver cells and multipotent mesenchymal stromal cells (MSCs) isolated from the bone marrow on an experimental model of chronic liver failure (CLF). Materials and methods. In creating liver CECs, the liver for decellularization and liver cells were obtained from male Wistar rats. MSCs were isolated from rat bone marrow. The functional efficacy of CEC was investigated on an experimental CLF model obtained by priming rats with $\mathrm{CCl}_{4}$ solution. At different periods after implantation, the outcomes were assessed based on the biochemical parameters of cytolysis. Morphological changes in the liver were analyzed by histochemical methods in the control (administration of saline solution into the liver parenchyma) and experimental (administration of liver CEC into the liver parenchyma) groups. Results. It was shown that implantation of the proposed CEC normalizes blood biochemical parameters and structural disorders of the damaged rat liver faster (by day 30 after introduction of CEC instead of day 180 in the control). The CEC was also shown to have reduced animal mortality from 50 to $0 \%$, which is due to early activation of proliferation of viable liver cells and faster formation of new blood vessels. These effects are down to either stimulation of the internal regenerative potential of the damaged liver during CEC implantation or long-term functioning of the transplanted cells as part of the CEC based on the decellularized liver matrix. Conclusion. The liver CEC, implanted into the liver parenchyma in laboratory animals with a CLF model, has a functional activity.
\end{abstract}

Keywords: liver, liver failure, regeneration, cell-engineered constructs, bioartificial organs, matrixes.

\section{BBEAEHИE}

Трансплантация печени является «золотым стандартом» для лечения пациентов с терминальной стадией заболеваний печени, однако дефицит донорских органов ограничивает широкое использование единственно радикального на сегодняшний день метода лечения декомпенсированных заболеваний печени. Значительное превышение количества пациентов, нуждающихся в трансплантации печени, над числом появляющихся органов, пригодных для пересадки, указывает на необходимость разработки альтернативных путей лечения, среди которых наиболее перспективно выглядит использование методов регенеративной медицины и тканевой инженерии $[1,2]$.

Большинство технических подходов в области тканевой инженерии печени основаны на выделении первичных гепатоцитов или получении из стволовых клеток гепатоцитоподобных клеток и их дальнейшем 3D-культивировании [3]. Отметим, что в составе клеточно-инженерных конструкций (КИК) при лечении ряда заболеваний печени целесообразно использовать мезенхимальные стромальные клетки для стимуляции регенерации органа [4]. Для обеспечения клеткам в составе КИК благоприятных условий для жизнедеятельности используют биосовместимые и биорезорбируемые матриксы.

Наибольший, с нашей точки зрения, интерес представляют собой децеллюляризованные носители/каркасы, относящиеся к классу биомиметиков внеклеточного матрикса (ВКМ) и получаемые путем удаления клеток и их фрагментов из ткани с максимальным сохранением структуры и состава естественного ВКМ $[5,6]$.

Множество работ посвящены децеллюляризации целого органа путем перфузии растворами поверхностно-активных веществ (ПАВ) и ферментов [7]. Подобный подход описан для сердца, почки, поджелудочной железы, матки [8-11]. Заметим, что децеллюляризация целой печени имеет ряд недостатков: низкая эффективность удаления клеточного детрита и сложность проникновения клеток, питательных веществ и газов в объем органа из-за нарушений микроциркуляции. В предыдущих работах нами был получен тканеспецифический матрикс из фрагментов децеллюляризованной печени крысы с сохранной структурой и отсутствием клеток и клеточных фрагментов [12]. Следующим логическим шагом является создание КИК печени, состоящей из тканеспецифического матрикса, клеток печени (КП) и 
мультипотентных мезенхимальных клеток костного мозга (ММСК КМ) с последующим доказательством ее функциональной эффективности на экспериментальной модели хронической печеночной недостаточности (ХПН), что и стало целью данной работы.

\section{МАТЕРИААЫ И МЕТОАЫ ИССАЕАОВАНИЯ}

Для решения поставленных задач проведены экспериментальные исследования на 60 крысах-самцах породы Вистар весом 250 г. Животных содержали в условиях вивария при температуре $18-20{ }^{\circ} \mathrm{C}$ на смешанном рационе питания при свободном доступе к воде. Эксперименты на животных проводились с 9 до 19 часов при комнатной температуре $\left(\mathrm{t}=22-24^{\circ} \mathrm{C}\right)$. Все манипуляции с животными проводили согласно правилам, принятым Европейской конвенцией по защите позвоночных животных, используемых для исследований и других научных целей (European Convention for the Protection of Vertebrate Animals Used for Experimtntal and other Scientifi c Purposes (ETS 123) Strasbourg, 1986).

Эксперименты были выполнены на 60 крысахсамцах породы Вистар весом 250 г. Из них 10 крыс были использованы в качестве доноров КП и 10 крыс - в качестве доноров печени для децеллюляризации. Срок эксперимента составил 180 суток наблюдения.

Фрагменты печени крыс $(\mathrm{n}=10)$ размером не более чем $2 \times 2 \times 2$ мм получали с использованием скальпеля и ножниц. Децеллюляризацию фрагментов печени крысы проводили в трех сменах фосфатносолевого буферного раствора (PBS) (138 мM NaCl, 2,67 мM KCl, 1,47 мM KH $\mathrm{PO}_{4}, 8,1 \mathrm{MM} \mathrm{Na} \mathrm{HPO}_{4}, \mathrm{pH}=$ $7,4)$, содержащего $0,1 \%$ додецилсульфата натрия и повышающуюся концентрацию Triton X-100: 1\%, 2\% и $3 \%$ [12]. Общее время децеллюляризации составляло 72 ч - по 24 ч для каждой смены раствора ПАВ при перемешивании на магнитной мешалке. Для получения микрочастиц фрагменты децеллюляризованной печени помещали в криомельницу CryoMill RETSCH (Retsch $\mathrm{GmbH}$, Германия) и измельчали в режиме, включавшем 3 цикла помола продолжительностью 3 минуты при частоте 25 Гц. Фракция частиц размером 100-250 мкм была выделена с применением сит соответствующих размеров.

Отмывка от ПАВ включала экспозицию матрикса в PBS, содержащем антибиотик (ампициллин, 20 мкг/мл) и антимикотик (амфотерицин В, 2,0 мкг/ мл) в течение 96 ч. Отмытые образцы стерилизовали $\gamma$-облучением в дозе 1,5 Мрад.

Работа по выделению КП и ММСК КМ и их культивированию проводилась в соответствии с общими принципами осуществления культуральных исследований на 10 крысах-самцах породы Вистар весом 250 г.
Для заселения децеллюляризованного матрикса печени клеточными компонентами по известной методике [15] использовали ранее установленное оптимальное соотношение клеток - КП : ММСК КМ = $5: 1$ [17]. Предварительное перед имплантацией сокультивирование КП и ММСК КМ осуществляли в том же соотношении $5: 1$ в течение 3 суток.

Следует отметить, что введение ММСК КМ в состав клеточной компоненты КИК обусловлено их способностью индуцировать процессы пролиферации клеток, в том числе за счет их собственной трансдифференцировки [17].

Функциональную эффективность полученной КИК печени оценивали на модели ХПН.

ХПН моделировали на крысах-самцах породы Вистар весом 250 г $(\mathrm{n}=40)$ путем затравки крыс раствором $\mathrm{CCl}_{4}$ по модифицированной нами схеме [16]. Контроль адекватности созданной модели ХПН оценивали по уровню летальности и выживаемости животных, состоянию биохимических показателей крови и морфологическим характеристикам состояния печени. На этапе моделирования ХПН 9 крыс погибло, что составило $22,5 \%$.

В результате после моделирования ХПН оставшиеся в живых крысы с экспериментальной моделью ХПН были разделены на 2 группы: контрольная группа 1 - 16 животных, в паренхиму поврежденной печени которым вводили физиологический раствор, и экспериментальная группа $2-15$ особей, в паренхиму поврежденной печени которым вводили КИК печени на 7-е сутки после окончания затравки $\mathrm{CCl}_{4}$. Иммуносупрессию не применяли.

Крыс контрольной и экспериментальной групп выводили из эксперимента на 28-30-е, 90-е и 180-е сутки путем внутрибрюшинного введения тиопентала натрия в дозировке, вызывающей остановку дыхания. На вышеуказанных сроках, перед полной остановкой дыхания, осуществляли забор венозной крови для биохимических исследований. Функцию печени (уровень АлАТ, АсАТ, билирубина, ГГТ, щелочной фосфатазы) исследовали с помощью биохимического анализатора Reflotron ${ }^{\mathrm{TM}}$ (Roche, Швейцария) при использовании специальных тестполосок Reflotron ${ }^{\mathrm{TM}}$ (точность измерения $\pm 0,5 \%$; воспроизводимость $\leq 0,2 \%$; линейность $\pm 0,05 \%$ ).

После полной остановки дыхания проводили эксплантацию печени для ее морфологических исследований. Осуществляли биопсию здоровой и поврежденной печени: печеночной недостаточности без лечения - контроль; печеночной недостаточности с лечением, исследования проводили в зонах имплантации КИК и вне зон имплантации КИК через 28-30, 90, 180 суток эксперимента. Оценивали данные световой микроскопии с окрашиванием срезов гематоксилином и эозином, по Ван-Гизону и по Маллори. 
Использовали микроскоп Leica DM 6000 В и камеру Leica LTDCH 9435 (Германия).

Морфометрический анализ осуществляли с использованием программы ImageScopeM (OOO «Системы для микроскопии и анализа», Россия) с использованием микроскопа Leica DM 1000 и камеры Leica LTDCH 9435 DFC 295 (Leica Camera AG, Германия). Морфометрически определяли наличие цирроза (подсчет количества ложных долек); удельную площадь соединительной ткани (в \% соотношении к общей площади среза печени) [18, 19].

Жизнеспособность КП в составе КИК печени оценивали с помощью иммуногистохимического метода окраски с гепатоцитоспецифическими антигенами (ОСН1ЕБ).

Статистическую обработку полученных результатов осуществляли с помощью компьютерного статистического пакета Biostat; достоверность различий оценивали по t-критерию Стьюдента с учетом поправки Бонферонни.

\section{РЕЗУАЬТАТЫ ИССАЕАОВАНИЯ И ИХ ОБСУЖАЕНИЕ}

После окончания затравки клиническое состояние выживших животных характеризовалось снижением массы тела, адинамией и частичным облысением животных. На протяжении всего времени эксперимента (180 суток) в контрольной группе на фоне $\mathrm{XПН} \mathrm{на} \mathrm{разных} \mathrm{сроках} \mathrm{дополнительно} \mathrm{погибло} \mathrm{еще}$ $50 \%(\mathrm{n}=8)$ крыс. В экспериментальной группе к этому же сроку выживаемость крыс составила 100\%. В связи с этим оценку функциональных и морфологических изменений в печени экспериментальных животных после моделирования ХПН исследовали на 8 и 15 крысах в контрольной и экспериментальной группах соответственно. Отсутствие летальности в экспериментальной группе позволило нам прийти к заключению о положительном влиянии имплантированной КИК на выживаемость крыс с моделью ХПН. На рис. 1 представлен макропрепарат печени крысы после окончания затравки, т. е. на 42-е сутки после начала затравки $\mathrm{CCl}_{4}$. Печень плотная и увеличена в размерах. Поверхность мелкобугристая, с закругленными краями.

Микроскопически уже в течение первого месяца после окончания затравки выявляли типичную картину цирротической трансформации архитектоники печени с прогрессирующим нарушением ее структуры на более поздних сроках наблюдения (особенно к 60-м и 90-м суткам) из-за разрастания соединительной ткани и формирующегося фиброза (рис. 2).

После децеллюляризации [12] фрагменты печени были отмыты полностью от КП (рис. 3) с последующем заселением полученного тканеспецифи-

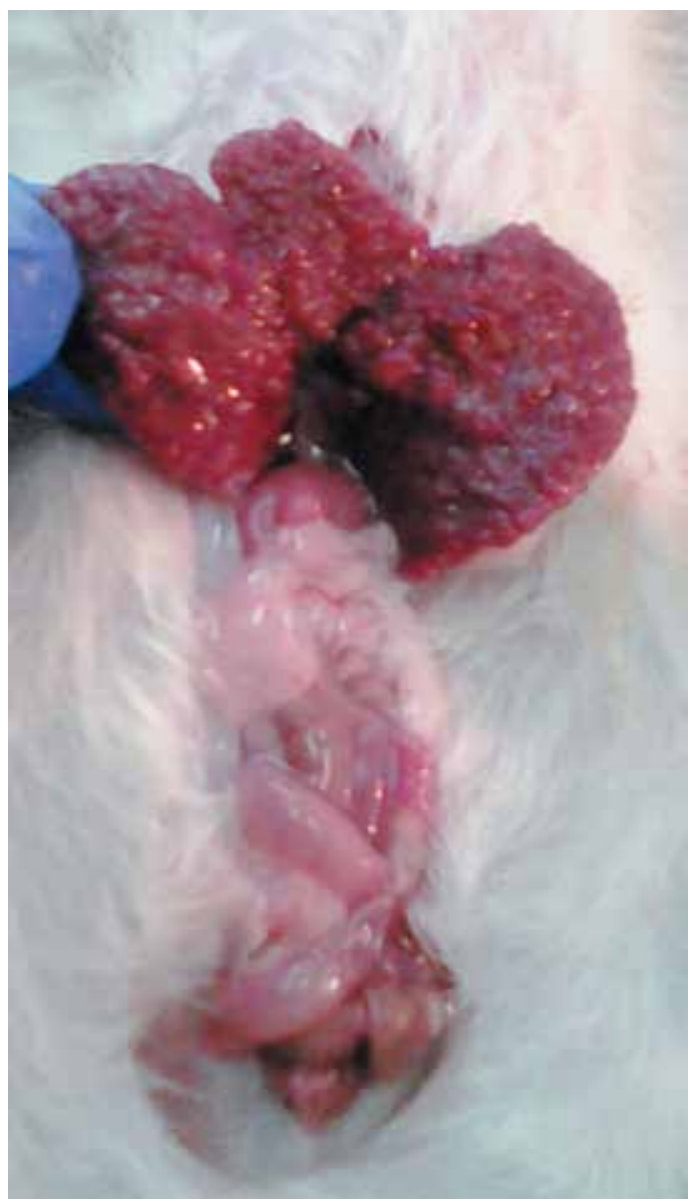

Рис. 1. Печень крысы после окончания токсического повреждения, 42-е сутки

Fig. 1. Rat liver after injection, 42 days

ческого матрикса клеточными компонентами КП и ММСК КМ.

Данные гистологического исследования, представленные на рис. 4, демонстрируют наличие адгезированных гепатоцитов на децеллюляризованном матриксе печени крысы.

Через 90 и 180 суток после имплантации КИК, представляющей собой мелкодисперсные частицы децеллюляризованной ткани печени с засеянными на ней КП и ММСК КМ в соотношении $5: 1$, были выявлены жизнеспособные и функционирующие гепатоциты (рис. 5).

На сроке 90 суток клетки донорской печени, сокультивированные с ММСК КМ, формировали в составе КИК ассоциаты жизнеспособных и функционально активных клеток. Выраженная воспалительная реакция и признаки отторжения отсутствовали. Аналогичные данные были получены на сроке 180 суток имплантации КИК.

Для количественной оценки изменений, возникающих в структуре печени крыс с моделью ХПН обеих групп, было проведено морфометрическое исследование состояния непаренхиматозных струк- 

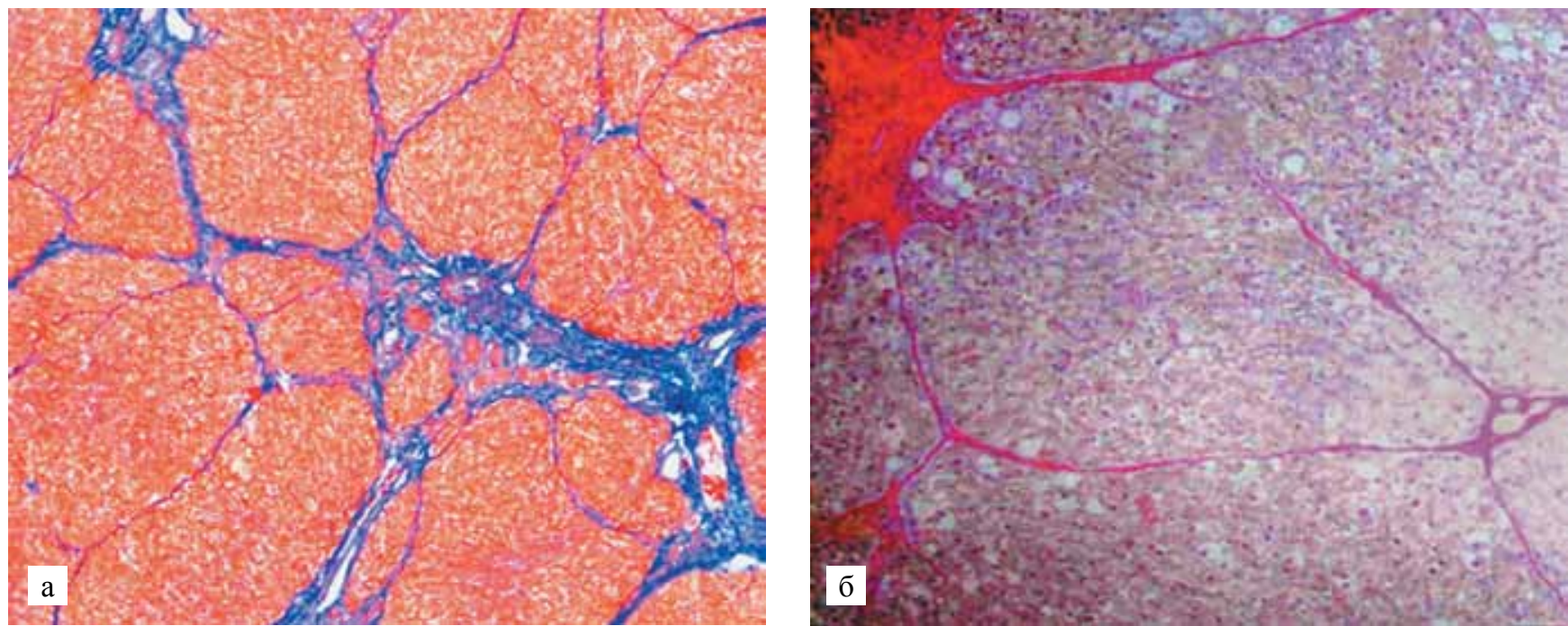

Рис. 2. Ткань печени крысы после окончания моделирования ХПН (затравка $\mathrm{CCl}_{4}=42$ суток): $\mathrm{a}-$ срок 90 суток, ложные дольки; окраска на соединительную ткань по Маллори; б - срок 180 суток, сформированные ложные дольки, склероз и цирроз печени; окраска по Ван-Гизону. ×100

Fig. 2. Rat liver tissue after CLF modeling $\left(\mathrm{CCl}_{4}\right.$ injection $=42$ days $)$ : a -90 days, false lobules; Mallory staining for connective tissue; $\sigma-180$ days, formed false lobules, sclerosis and cirrhosis; Van Gieson's stain. $\times 100$

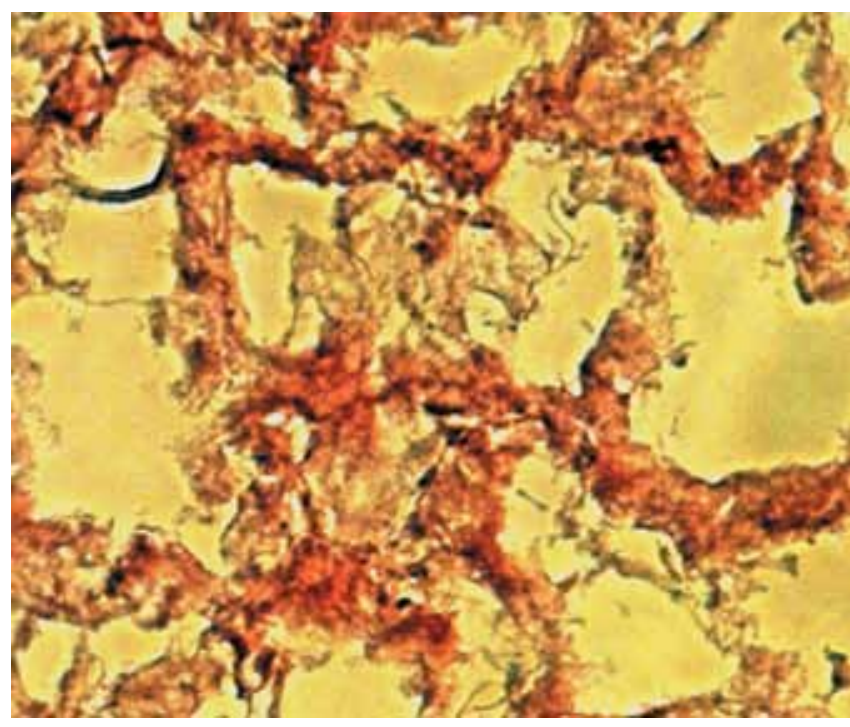

Рис. 3. Фрагмент децеллюляризованной печени крысы. Окраска гематоксилином и эозином. $\times 200$

Fig. 3. Fragment of decellularized rat liver. H\&E stain. $\times 200$

тур (определение удельной площади соединительной ткани и количества ложных долек в печени) на разных сроках в течение 180 суток. Было установлено, что в группе 2 через 60-90 суток после введения КИК печени происходит восстановление как паренхимы, так и непаренхиматозных структур. Это подтверждает динамическое морфометрическое исследование снижения удельной площади соединительной ткани печени и количества ложных долек в ней (рис. 6).

Оценку функции печени проводили в динамике путем измерения биохимических показателей сыво-

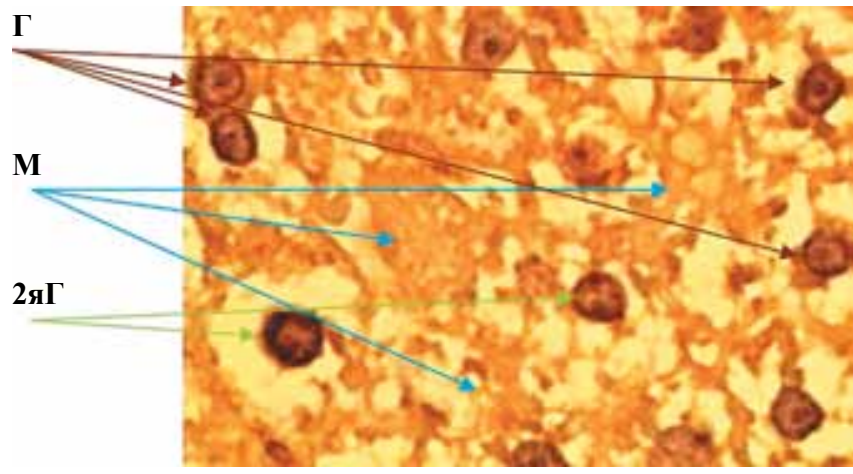

Рис. 4. Гепатоциты, адгезированные на тканеспецифическом матриксе печени. М - децеллюляризованный матрикс печени; Г - адгезированные гепатоциты; 2яГ двуядерные гепатоциты. Окраска гематоксилином и эозином. $\times 400$

Fig. 4. Hepatocytes adhered to the tissue-specific liver matrix. $\mathrm{M}$ - decellularized liver matrix; $\Gamma$-adhered hepatocytes; 2яГ - binuclear hepatocytes. H\&E stain. $\times 400$

ротки крови. Определение уровня ферментов цитолиза (АлАТ; АсАТ; ЩФ) в сыворотке крови животных (рис. 7) позволило установить резкое повышение уровня этих ферментов в течение первых 2 недель затравки. После окончания затравки спустя 7 суток уровень АлАТ и АсАТ повысился более чем в 4,5 и 3 раза соответственно, а уровень ЩФ увеличился почти в 5 раз. Спустя 28-30 суток после окончания затравки уровни ферментов цитолиза снижались, но продолжали длительно оставаться на достоверно (p < $0,05)$ более высоком уровне (рис. 7) по сравнению 

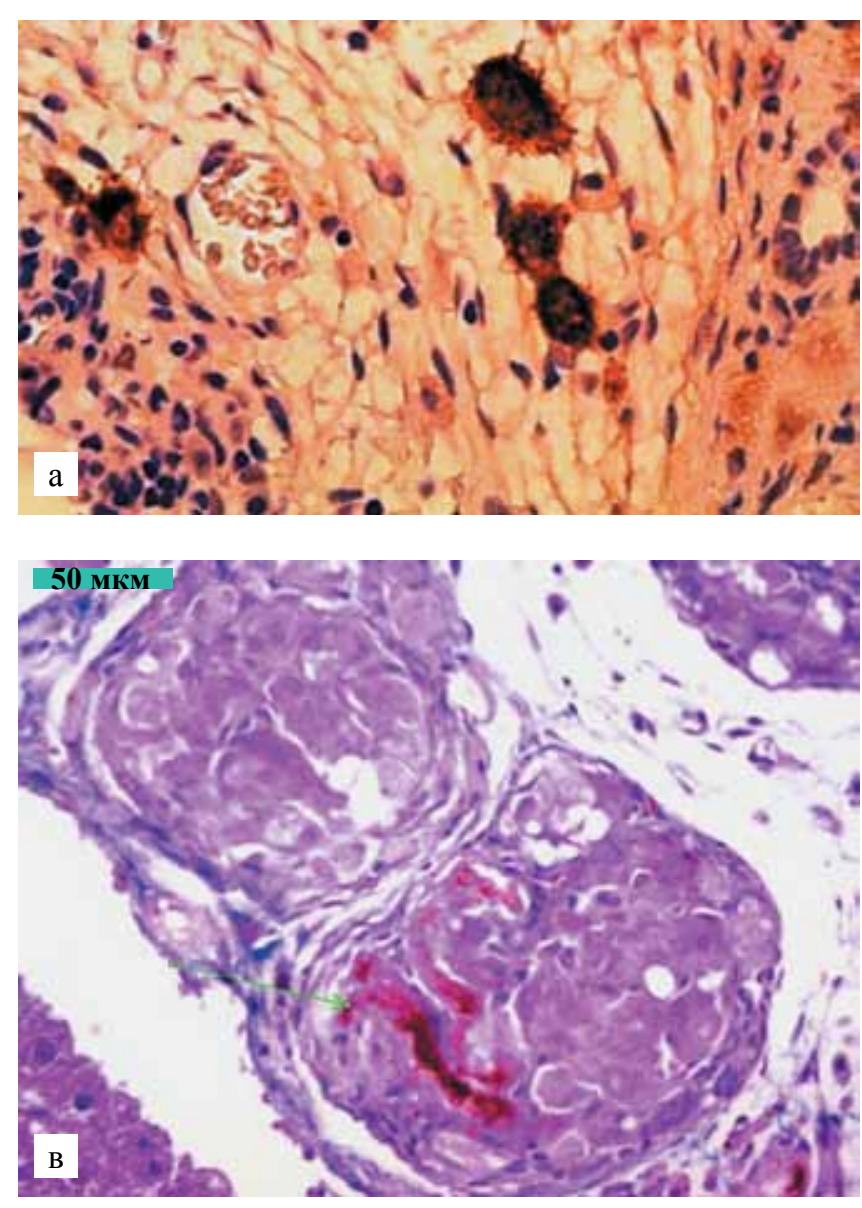

a

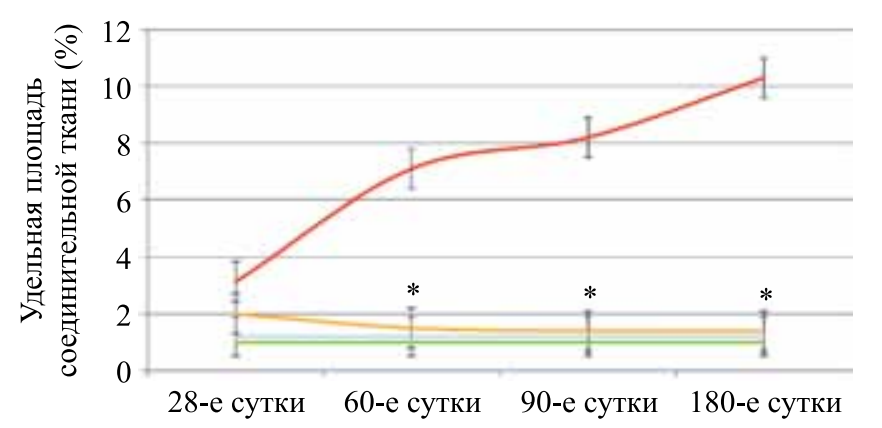

6

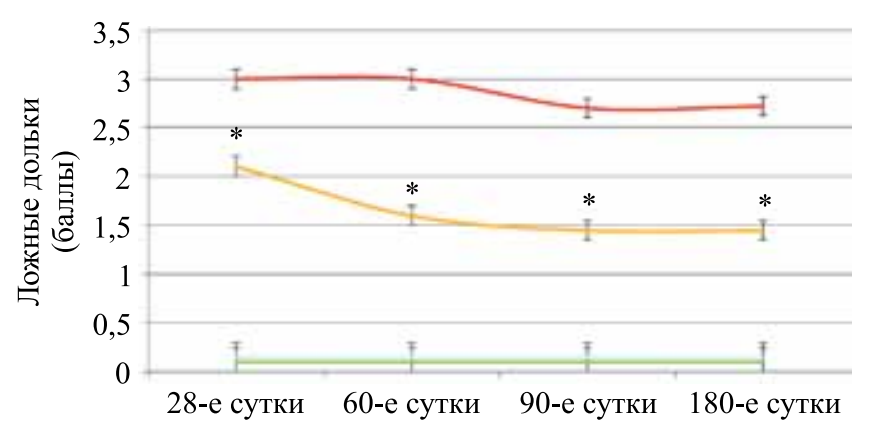

— Норма — Исходный

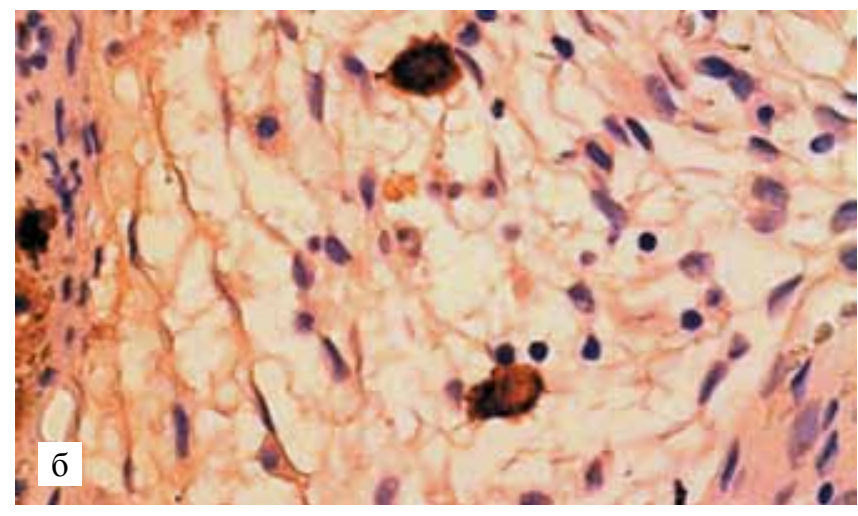

Рис. 5. Гистологические препараты печени в зоне трансплантации КИК (КП : ММСК КМ = $5: 1)$ в паренхиму поврежденной печени: жизнеспособные гепатоциты на сроке 90 (а) и 180 (б) суток. Иммуногистохимическое исследование с гепатоцитоспецифическими антигенами (ОСН1ЕБ) - положительное гранулярное цитоплазматическое окрашивание; в - продукция желчи (зеленая стрелка) пересаженными гепатоцитами. Окраска гематоксилином и эозином. $\times 400$

Fig. 5. Histological liver preparations in the CEC transplanted area (LC : MMSC BM = 5:1) in the parenchyma of the damaged liver: viable hepatocytes at 90 (a) and 180 (б) days. Immunohistochemical study with hepatocyte-specific antigens (OCH1E5) - positive granular cytoplasmic staining; B - bile production (green arrow) by transplanted hepatocytes. $H \& E$ stain. $\times 400$

Рис. 6. Динамическая морфометрическая оценка состояния непаренхиматозных структур печени крыс при моделировании хронической печеночной недостаточности и имплантации КИК: а - изменение удельной площади соединительной ткани; б - подсчет количества ложных долек в печени. Группа 1 - контроль (физиологический раствор); группа 2 - КИК печени. * - Различие достоверно по сравнению с уровнем показателя в печени крыс контрольной группы, $\mathrm{p}<0,05$

Fig. 6. Dynamic morphometric assessment of the state of non-parenchymal structures of the rat liver during CLF modeling and CEC implantation: a - change in the specific area of connective tissue; $\sigma$ - counting the number of false lobules in the liver. Group 1 - control (saline); group 2 - liver CEC. * - The difference is significant compared to the level of the indicator in the rat liver in the control group, $\mathrm{p}<0.05$

с нормальными показателями у интактных животных на протяжении 180 суток. В экспериментальной группе также наблюдали цитолитические процессы в паренхиматозных клетках печени, но которые были достоверно менее интенсивные, чем в контрольной группе, а соответствующие показатели достигали нормальных значений к 30-м суткам после имплантации КИК, тогда как в контроле нормализация значе- 


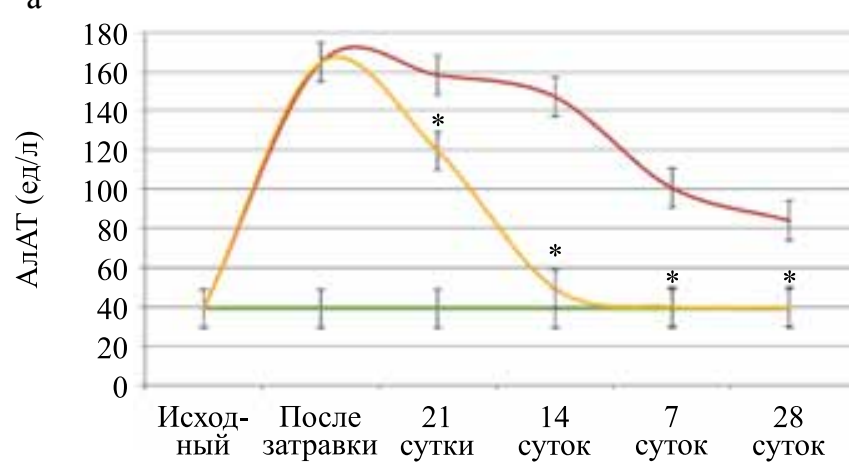

B

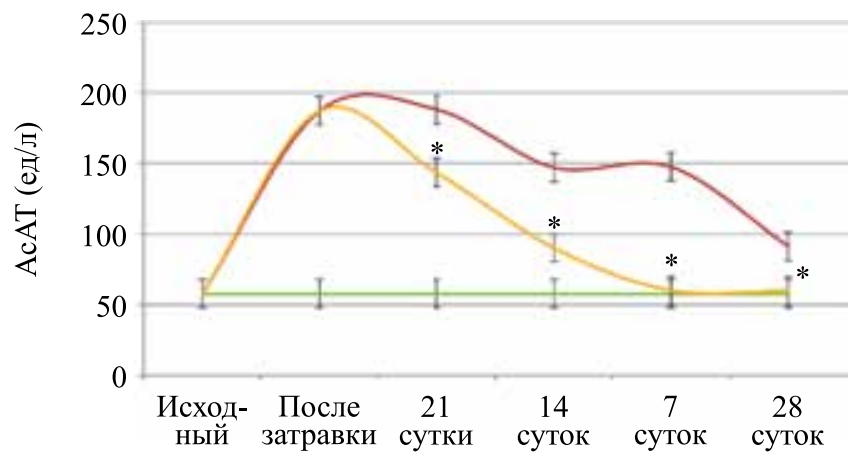

Д

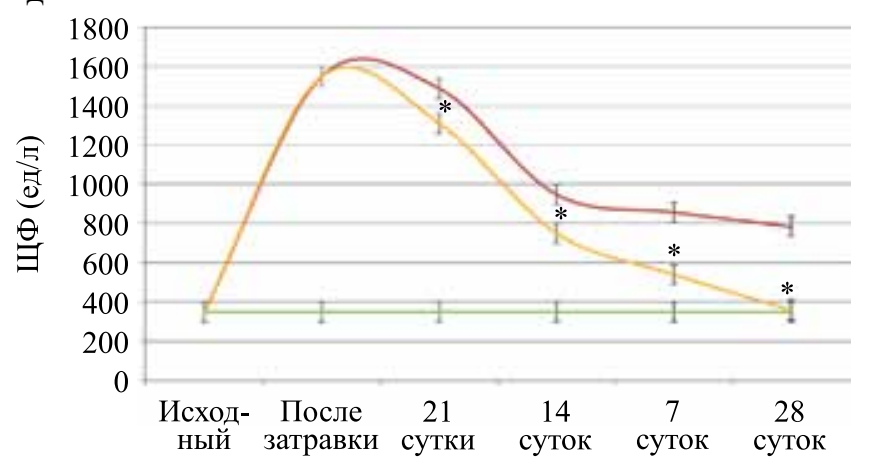

б

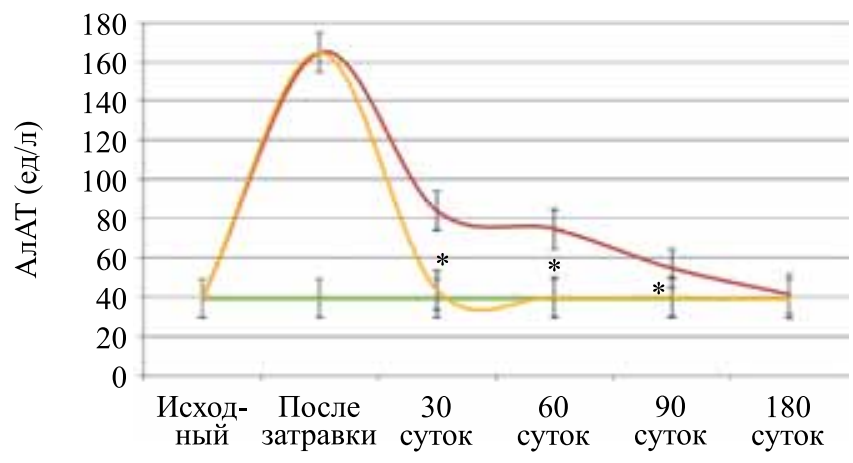

$\Gamma$
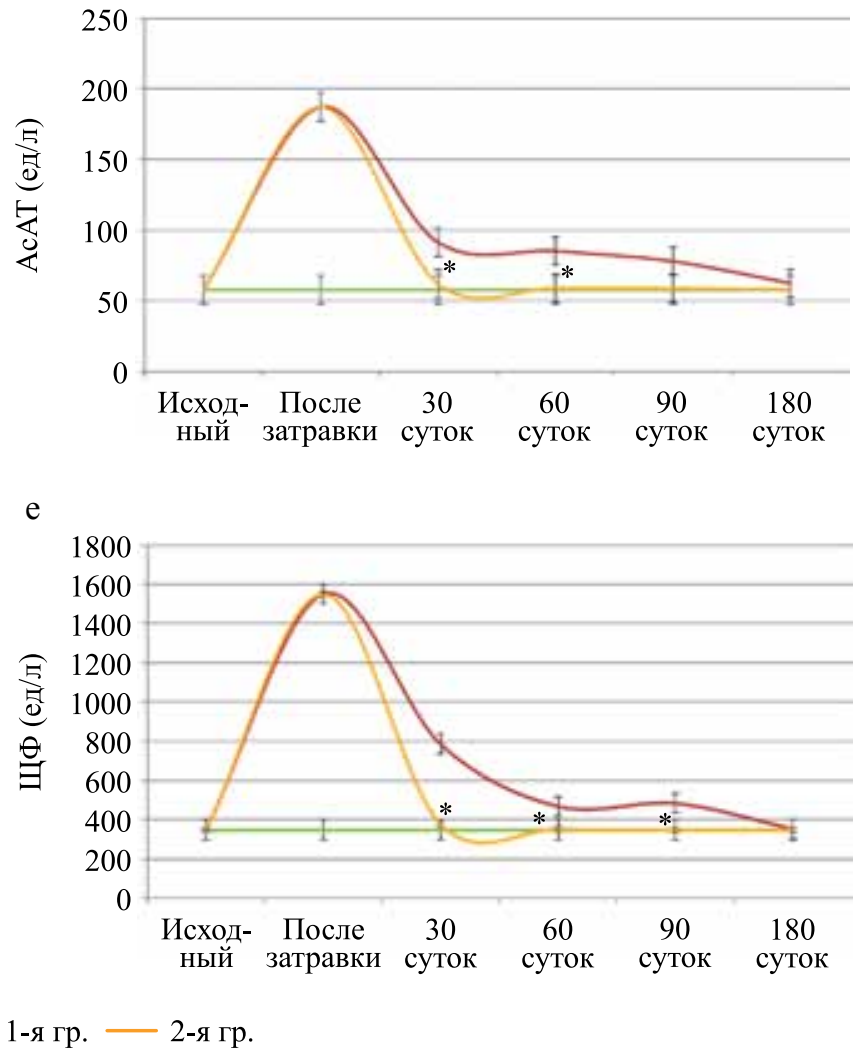

Рис. 7. Динамика нормализации уровня ферментов цитолиза (АлАТ, АсАТ, ЩФ) в сыворотке крови крыс после моделирования хронической печеночной недостаточности и имплантации КИК. Уровень для здоровых животных: АлАТ до 40 ед/л; АсАТ - до 60 ед/л; ЩФ - до 350 ед/л; а, в, д - срок наблюдения 28 суток; б, г, е - срок наблюдения 180 суток. * - Различие достоверно по сравнению с уровнем ферментов в контроле (группа 1); p < 0,05

Fig. 7. Dynamics of normalization of the cytolysis enzymes level (ALT, AST, ALP) in the blood serum of rats after CLF modeling and CEC implantation. Level for healthy rats: ALT up to $40 \mathrm{IU} / \mathrm{L}$; AST - up to $60 \mathrm{IU} / \mathrm{L}$; ALP - up to 350 IU/L; a, B, д - observation period 28 days; $б$, г, e-observation period 180 days. ${ }^{*}$ - The difference is significant compared to the level of enzymes in the control (group 1); $p<0.05$

ний АсАТ, АлАТ и ЩФ наступала только к 180-м суткам эксперимента (рис. 7).

Уровень гамма-глютамилтранспептидазы ( $\gamma$-ГТП) и билирубина в сыворотке крови экспериментальных животных на всех сроках наблюдения оставался в пределах нормальных значений.

Наблюдаемые эффекты можно объяснить либо стимулированием внутреннего регенеративного потенциала поврежденной печени при импланта- ции КИК, либо активным функционированием пересаженных клеток в составе КИК на основе децеллюляризованного матрикса печени.

\section{ЗАКАЮЧЕНИЕ}

Показано, что имплантация предложенной КИК обеспечивает более быструю нормализацию биохимических показателей крови и структурных нарушений поврежденной печени крыс (к 30-м суткам 
после введения КИК вместо 180 суток в контроле) и снижение летальности животных с $50 \%$ до $0 \%$, что обусловлено более ранней активацией процессов пролиферации жизнеспособных КП и более быстрым формированием новых кровеносных сосудов.

Таким образом, полученные результаты доказывают наличие функциональной активности КИК печени, имплантируемой в паренхиму печени лабораторным животным с моделью ХПН.

\section{Авторы заявляют об отсутствии конфликта интересов.}

The authors declare no conflict of interest.

\section{СПИСОК АИТЕРАТУРЫ / REFERENCES}

1. Salim MS, Issa AM, Farrag ARH, Gabr H. Decellularized liver bioscaffold: a histological and immunohistochemical comparison between normal, fibrotic and hepatocellular carcinoma. Clin Exp Hepatol. 2019; 5 (1): 35-47. doi: 10.5114/ceh.2019.83155.

2. Acun A, Oganesyan R, Uygun BE. Liver bioengineering: promise, pitfalls, and hurdles to overcome. Curr Transplant Rep. 2019; 6 (2): 119-126. doi: 10.1007/s40472019-00236-3.

3. Mazza G, Al-Akkad W, Rombouts K, Pinzani M. Liver tissue engineering: from implantable tissue to whole organ engineering. Hepatol Commun. 2017; 2 (2): 131141. doi: 10.1002/hep4.1136.

4. Elchaninov A, Fatkhudinov T, Usman N, Arutyunyan I, Makarov A, Lokhonina A et al. Multipotent stromal cells stimulate liver regeneration by influencing the macrophage polarization in rat. World J Hepatol. 2018; 10 (2): 287-296. doi: 10.4254/wjh.v10.i2.287.

5. Crapo PM, Gilbert TW, Badylak SF. An overview of tissue and whole organ decellularization processes. Biomaterials. 2011; 32 (12): 3233-3243. doi: 10.1016/j.biomaterials.2011.01.057.

6. Uygun BE, Yarmush ML, Uygun K. Application of wholeorgan tissue engineering in hepatology. Nature Reviews Gastroenterology \& Hepatology. 2012; 9 (12): 738-744. doi: 10.1038/nrgastro.2012.140.

7. Rossi EA, Quintanilha LF, Nonaka CKV, Souza BSF. Advances in hepatic tissue bioengineering with decellularized liver bioscaffold. Stem Cells Int. 2019; 2019: 2693189. doi: 10.1155/2019/2693189.

8. Ferng AS, Connell AM, Marsh KM, Qu N, Medina AO, Bajaj $N$ et al. Acellular porcine heart matrices: whole organ decellularization with 3D-bioscaffold \& vascular preservation. J Clin Transl Res. 2017; 3 (2): 260-270.

9. Figliuzzi M, Bonandrini B, Remuzzi A. Decellularized kidney matrix as functional material for whole organ tissue engineering. J Appl Biomater Funct Mater. 2017; 15 (4): e326-e333. doi: 10.5301/jabfm.5000393.

10. Kuna VK, Kvarnström N, Elebring E, Holgersson SS. Isolation and decellularization of a whole porcine pan- creas. J Vis Exp. 2018; (140): 58302. doi: 10.3791/58302. PMID: 30371658.

11. Daryabari SS, Kajbafzadeh AM, Fendereski K, Ghorbani F, Dehnavi M, Rostami $M$ et al. Development of an efficient perfusion-based protocol for whole-organ decellularization of the ovine uterus as a human-sized model and in vivo application of the bioscaffolds. J Assist Reprod Genet. 2019; 36 (6): 1211-1223. doi: 10.1007/ s10815-019-01463-4.

12. Готье СВ, Севастьянов ВИ, Шагидулин МЮ, Немеи ЕА, Басок ЮБ. Тканеспецифический матрикс для тканевой инженерии паренхиматозного органа и способ его получения. Патент на изобретение RU 2693432 C2, 02.07.2019. Gautier SV, Sevastyanov VI, Shagidulin MYu, Nemets EA, Basok YuB. Tkanespetsificheskiy matriks dlya tkanevoy inzhenerii parenkhimatoznogo organa i sposob ego polucheniya. Patent na izobretenie RU 2693432 C2, 02.07.2019.

13. Шумаков ВИ, Онищенко НА. Биологические резервы клеток костного мозга и коррекция органных дисфункций: [монография]. М.: Лавр, 2009. 307. Shumakov VI, Onishhenko NA. Biologicheskie rezervy kletok kostnogo mozga i korrekcija organnyh disfunkcij: [monografija]. M.: Lavr, 2009. 307.

14. Готье СВ, Шагидулин МЮ, Онищенко НА, Краменинников МЕ, Никольская АО, Башкина ЛВ, Севастьянов ВИ. Способ лечения печеночной недостаточности. Патент на изобретение RU 2586952 C1, 10.06.2016. Gautier SV, Shagidulin MYu, Onishhenko NA, Krasheninnikov ME, Nikol'skaja AO, Bashkina LV, Sevast'janov VI. Sposob lechenija pechenochnoj nedostatochnosti. Patent na izobretenie RU 2586952 C1, 10.06.2016.

15. Шагидулин МЮ, Онищенко НА, Крашенинников МЕ, Ильинский ИМ, Можейко НП, Шмерко НП и др. Выживание клеток печени, иммобилизированных на 3D-матриксах при моделировании печеночной недостаточности. Вестник трансплантологии и искусственных органов. 2011; 13 (3): 59-66. Shagidulin MYu, Onishchenko NA, Krasheninnikov ME, Iljinsky IM, Mogeiko NP, Shmerko NP et al. Survival of liver cells, immobilized on 3d-matrixes, in liver failure model. Russian Journal of Transplantology and Artificial Organs. 2011; 13 (3): 59-66. [In Russ, English abstract]. doi: 10.15825/1995-1191-2011-3-59-66.

16. Никольская АО, Гоникова 33, Кирсанова ЛА, Шагидулин МЮ, Онищенко НА, Севастьянов ВИ. Способ моделирования тяжелого спонтанно необратимого повреждения печени. Патент на изобретение RU 2633296 C, 11.10.2017. Nikolskaja AO, Gonikova ZZ, Kirsanova LA, Shagidulin MJu, Onishhenko NA, Sevast'janov VI. Sposob modelirovanija tjazhjologo spontanno neobratimogo povrezhdenija pecheni. Patent na izobretenie RU 2633296 C, 11.10.2017.

17. Шагидулин МЮ, Онищенко НА, Крашенинников МЕ, Никольская АО, Волкова ЕА, Ильинский ИМ и др. Влияние соотношения клеток печени и костного мозга в 
имплантируемых клеточно-инженерных конструкциях на эффективность восстановительных процессов в печени при хронической печеночной недостаточности. Вестник трансплантологии и искусственных органов. 2019; 21 (1): 122-134. Shagidulin MYu, Onishchenko NA, Krasheninnikov ME, Nikol'skaja AO, Volkova EA, Il'inskij IM et al. The influence of the ratio of liver cells and bone marrow in the implantable cell-engineering structures of the liver on the recovery efficiency of functional and morphological parameters in chronic liver failure. Russian Journal of Transplantology and Artificial Organs. 2019; 21 (1): 122-134. [In Russ, English abstract]. doi: 10.15825/1995-1191-20191-122-134.
18. Автандилов ГГ. Медицинская морфометрия. Руководство. М.: Медицина, 1990. 384. Avtandilov GG. Medicinskaja morfometrija. Rukovodstvo. M.: Medicina, 1990. 384.

19. Ishak K, Baptista A, Bianchi L, Callea F, Grootes J et al. Гистологическая оценка стадии и степени хронического гепатита. Клиническая гепатология. 2010; 2: 8-11. Ishak K., Baptista A, Bianchi L, Callea F, Grootes $J$ et al. Gistologicheskaya ocenka stadii i stepeni hronicheskogo gepatita. Klinicheskaya gepatologiya. 2010; 2: $8-11$.

Статья поступила в редакиию 14.10.2020 2. The article was submitted to the journal on 14.10.2020

УВАЖАЕМЫЕ ЧИТАТЕАИ!

ПоАПиску на журна^ «Вестник трансп^анто^огиИ И искусственных органов» можно офрормить в ближайшем к вам почтовом отАелении.

ПоАписной инАекс НаШеГО ИзАания в Ката^оГе «Газеты и журналы» - 80248

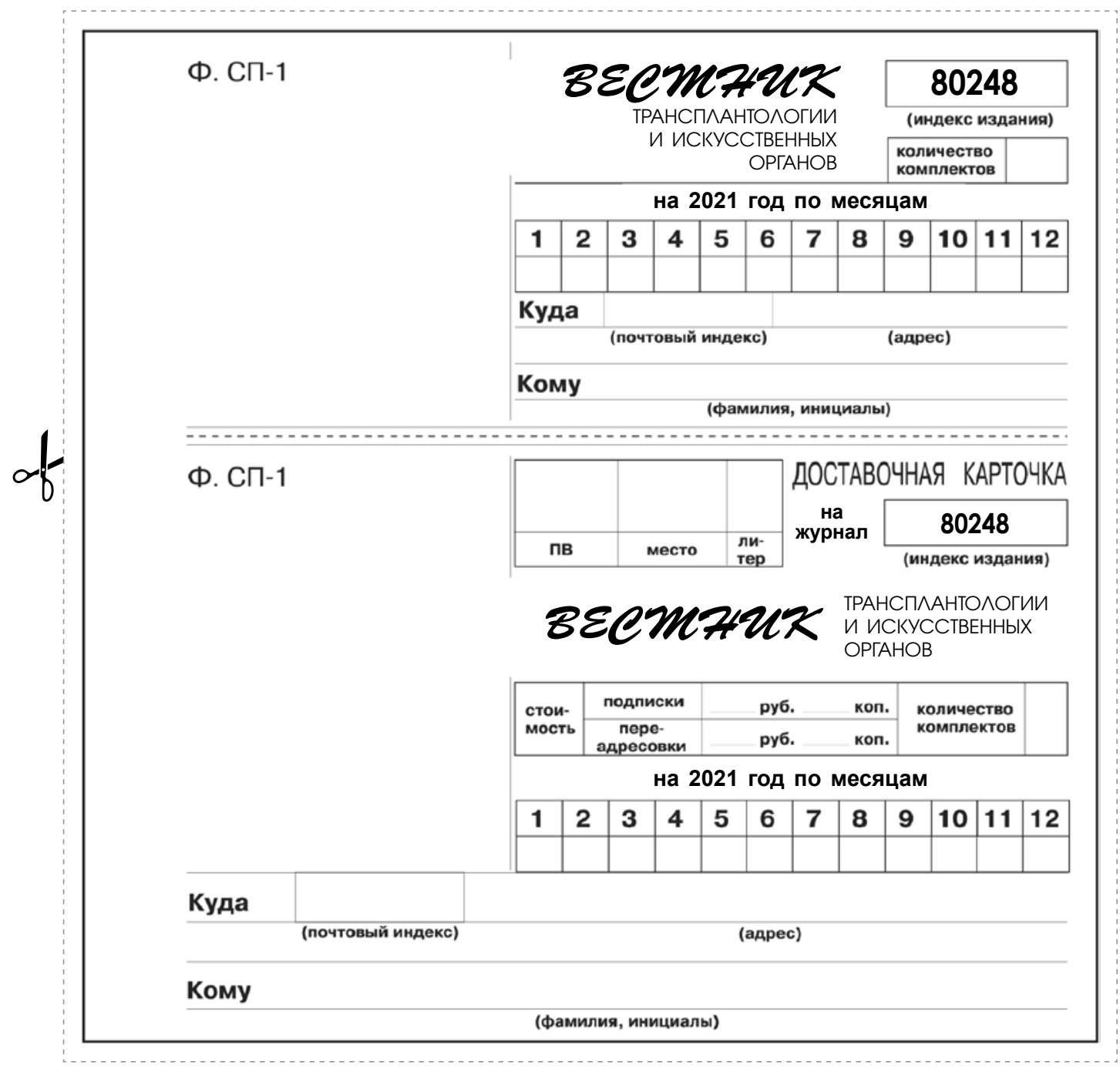

